\title{
Artyfechinostomum sufrartyfex Trematode Infections in Children, Bihar, India
}

\section{Yugal K. Prasad, ${ }^{1}$ Suman Dahal, ${ }^{1}$ Barsha Saikia, Bobita Bordoloi, Veena Tandon, Sudeep Ghatani}

Eating raw or insufficiently cooked mollusks is a known risk factor for human echinostomiasis. We confirmed identification of Artyfechinostomum sufrartyfex trematodes as the causative agent of disease among 170 children in northern Bihar, India. We also identified the snail Pila globosa as a potential source of infections in the study area.

F oodborne intestinal trematodiasis, especially that caused by members of the family Echinostomatidae, is an emerging yet neglected public health disease. Approximately 24 echinostome species cause human echinostomiasis and are highly endemic to Southeast Asia and the Far East; major foci are located in China, India, Indonesia, South Korea, Malaysia, the Philippines, and Thailand (1).

Previously, only 2 deaths attributed to the echinostomid fluke Artyfechinostomum sufrartyfex were reported from the states of Assam and Tamil Nadu in India $(2,3)$. During 2004-2017, several cases of echinostome infection were reported in children at Shri Shubh Lal Hospital and Research Centre in Bihar, India.

\section{The Study}

This study was approved by the Institutional Ethics Committee of Sikkim University (SU/IEC/2017/04), Gangtok, India. A total of 170 cases of $A$. sufrartyfex trematode infection occurred in northern Bihar, India, mostly in children $\leq 12$ years of age. The children lived in the districts of Sitamarhi and Sheohar in the state of Bihar. Signs and symptoms were diarrhea (persistent/chronic and acute) with watery or mucus-bound stool, vomiting, loss of appetite, weakness, passage of red worms in stool or vomit, swelling of the feet and the entire body, fever, cough, breathlessness, night blindness, and urticarial rashes (Table 1).

Physical examination showed that most patients were anemic. Clinical laboratory investigations showed

Author affiliations: Shri Shubh Lal Hospital and Research Centre, Sitamarhi, India (Y.K. Prasad); Sikkim University, Gangtok, India (S. Dahal, B. Saikia, B. Bordoloi, S. Ghatani); Biotech Park, Lucknow, India (V. Tandon)

DOI: https://doi.org/10.3201/eid2508.181427 leukocytosis and eosinophilia. However, systemic examination showed no adverse effects of the cardiovascular, abdominal, and central nervous systems (Table 2). Levels of serum alanine aminotransferase, bilirubin, blood urea, creatinine, electrolytes, sodium, potassium, and chloride were within reference limits.

These children were immediately hospitalized and kept under careful observation with routine monitoring of stool and vomit for worms. Once worms were observed in samples, the patients were given praziquantel $(75 \mathrm{mg} /$ $\mathrm{kg}$ in 3 divided doses orally for 2 days) and monitored. At administration of the drug, patients started passing more worms in stool. We recovered $>50$ worms but $\leq 300$ worms from each child patient. The infection subsided after the standard dose of praziquantel, and most patients recovered from the infection.

However, we observed 11 deaths: 2 patients each during 2004, 2007, 2008, 2012, and 2013 and 1 patient during 2009. Severe acute malnutrition with or without edema and large numbers of worms were major clinical conditions observed for these deaths. Nine children had persistent diarrhea with severe dehydration and shock, and 2 of them had acute diarrhea, severe dehydration, and shock.

The infected patients frequently consumed raw snails. The most prevalent snail species in the study areas was Pila globosa, which the children collected from the banks of ponds/ditches and waterlogged paddy fields grossly contaminated with human and animal excreta (168/170 cases, $99 \%$ ). Therefore, we surveyed as many as 8 sites in 2 districts (Sitamarhi and Sheohar) for snail samples from their natural habitats (Figure 1).

We screened the snails by using a digestion technique with a $0.5 \%$ pepsin $/ 0.1 \% \mathrm{HCl}$ solution and found that the snails were heavily infected with metacercariae, which are the encysted infective stage of the trematode. The prevalence of metacercariae in the snails ranged from $16.12 \%$ in Hanumannagar to $\leq 48.19 \%$ in Punaura (Appendix, https://wwwnc.cdc.gov/EID/article/25/8/181427-App1.pdf).

To establish the source of infection, we attempted to identify the clinical parasite samples and the metacercariae. We morphologically identified representative parasite samples isolated from the patients $(2,4,5)$. However, we could not identify metacercaria by only morphologic characteristics

${ }^{1}$ These authors contributed equally to this article. 


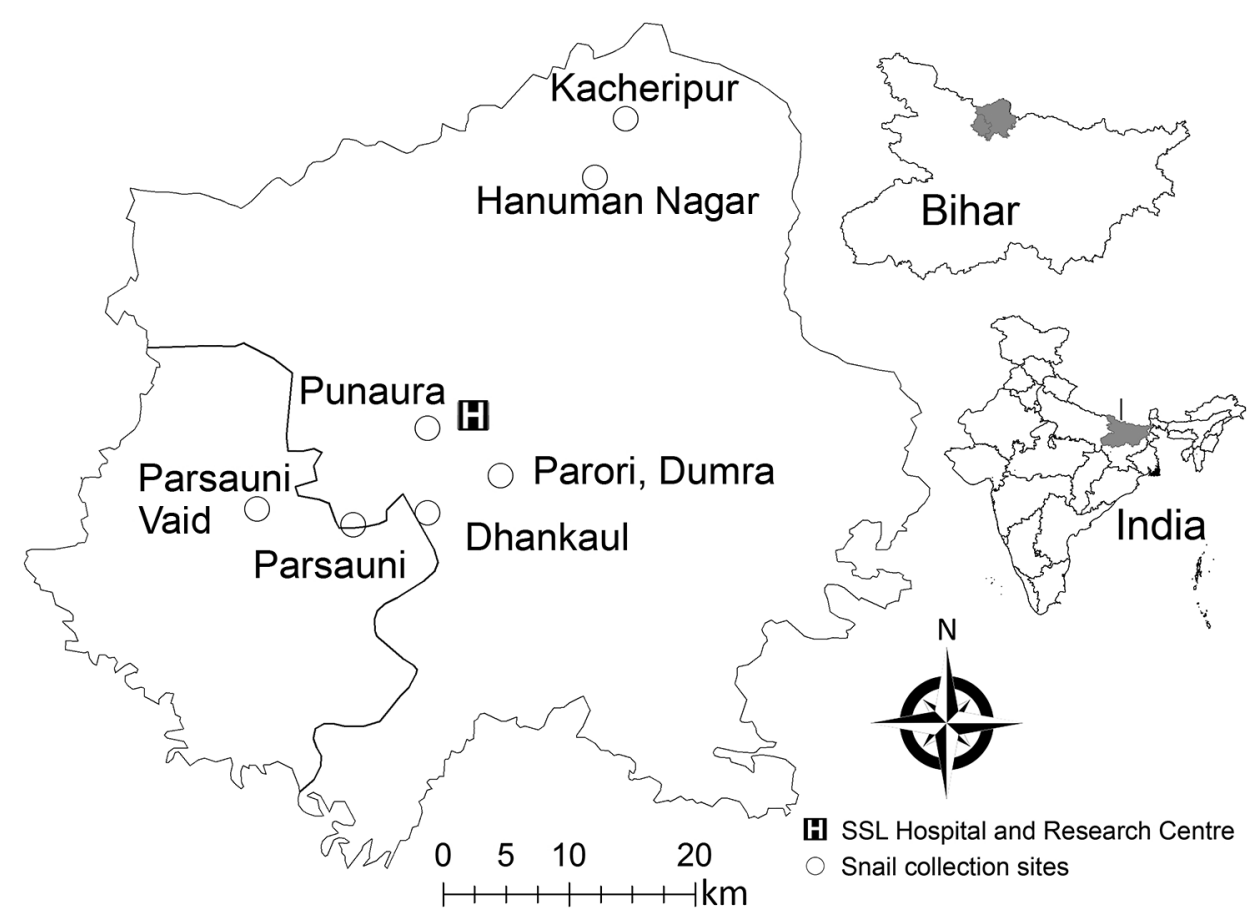

Figure 1. Collection sites of clinical samples from patients infected with Artyfechinostomum sufrartyfex trematodes at SSL Hospital and Research Center, Sitamarhi, Bihar, India. Black border indicates district boundary. Insets show location of Sitamarhi in Bihar and location of Bihar in India. SSL, Shri Shubh Lal.

(Figure 2). Therefore, we used a molecular approach to confirm the identity of the life cycle stages.

We isolated total genomic DNA from individual adult trematodes (6). For metacercariae, we isolated genomic DNA from $\approx 200$ cysts/isolation by using a DNA Isolation Kit (Macherey-Nagel, https://www.mn-net.com) according to the manufacturer's protocol. We then amplified and sequenced nuclear 28S rRNA and internal transcribed spacer (ITS) 2 genes and the mitochondrial cytochrome c oxidase (COI) gene for both stages by using universal trematode primers (7-9). Individual gene regions tested were $1,042 \mathrm{bp}$ for the 28S rRNA gene, $433 \mathrm{bp}$ for ITS2 gene, and $343 \mathrm{bp}$ for the mitochondrial COI gene. We deposited sequences in GenBank (accession nos. MH236132-3, MH237730-1, and MH253673-4).

For specific identification of the parasites, we performed a blastn search (https://blast.ncbi.nlm.nih.gov/Blast.cgi). The 28S rRNA and mitochondrial COI gene regions showed maximum sequence identity with GenBank accession no. KF781303.1 for A. sufrartyfex (99\%) and accession no. NC037150.1 for A. sufrartyfex from Shillong, India (100\%). For the ITS2 gene region, we observed maximum sequence identity with GenBank accession no. JF412727 Echinostoma malayanum from Khon Kaen, Thailand (99\%), and with accession no. EF027100.1 A. sufrartyfex from Meghalaya, India (96\%). On the basis of these findings, we concluded that clinical specimens and metacercariae isolated from $P$. globosa snails were the same species (A. sufrartyfex).

Furthermore, we generated barcode sequences by using trematode-specific primers (10) and deposited them in the BOLD database (BOLDSYSTEMS version, http:// www.boldsystems.org). We obtained unique barcodes for both life cycle stages (identification no. BIN URIBOLD:ADM2711). The barcode sequence had a length of $777 \mathrm{bp}$. To check for its specificity, we performed a similarity search across the BOLD database by using the BOLD Identification System. This search showed that our sequences were highly species specific; the closest match with other species was with Nephrostomum limai worms (83.24\% identity).

\section{Conclusions}

Our findings conclusively establish that these children were infected with $A$. sufrartyfex trematodes. We identified the causal agent and its infective metacercarial stage as $A$. sufrartyfex trematodes by using morphologic and molecular approaches. For ease of accurate identification in the future, we also provide unique DNA barcodes for the species.

Overall, we detected 170 infected case-patients and 11 deaths from these infections. Because of lack of proper diagnostic tools available to medical practitioners in the affected parts, several other infection cases might have remained undefined. This trematode species poses a serious threat to public health in this part of India and, if not contained early, might spread to other and nonendemic areas of the region.

We also report the prevalence of trematode metacercariae in $P$. globosa snails from foci of infections in Bihar, thus implicating this snail species as the potential source of infection. At the same time, we found 

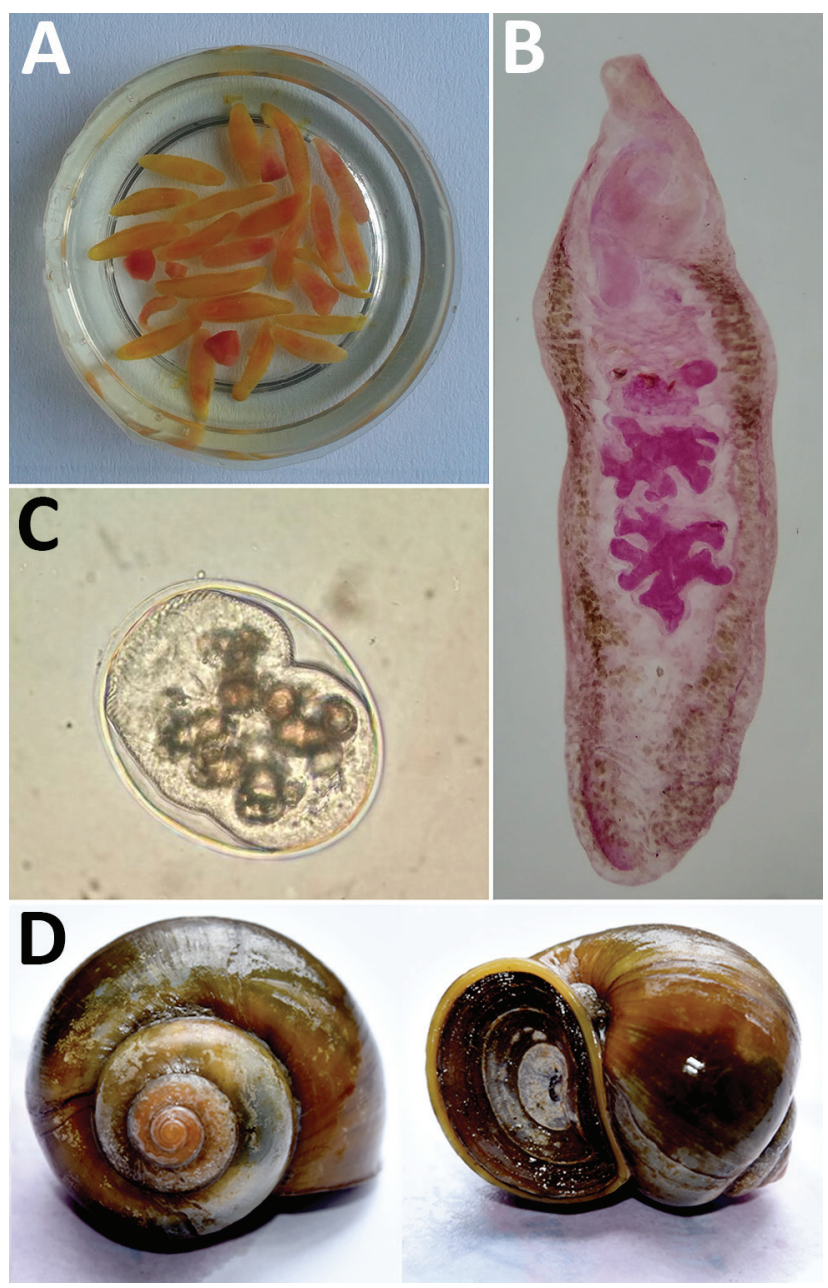

Figure 2. Artyfechinostomum sufrartyfex trematodes isolated from infected patients in Bihar, India. A) Trematodes in physiologic saline collected from stool samples. B) Whole mount of an adult trematode (acetocarmine stain). C) Metacercaria isolated from Pila globosa snails. Original magnification $\times 400$. D) Pila globosa snails, the second intermediate host of the trematode.

metacercaria prevalence to be quite high, which is indicative of greater transmission risk to the inhabitants who are eating raw snails.

We found the DNA barcodes generated for life cycle stages to be unique in the entire BOLD database. Therefore, we expect these barcodes to act as references for easy and accurate diagnosis of the disease in the future.

We observed that some high-risk practices, such as open defecation in the infected areas, are still rampant, which is a cause of concern because this practice helps maintain the parasite cycle in the environment. However, a cleanliness program, such as the Swachh Bharat Mission started by the Government of India (http://sbm.gov.in/sbmreport/home.aspx), and installing toilets in every household in rural areas might immensely help to contain the parasite infection.

\section{Acknowledgments}

We thank the hospital staff at Shri Shubh Lal Hospital and Research Centre for providing help with sample collection and Sailendra Dewan for designing Figure 1.

This study was supported by the Science and Engineering Research Board, Department of Science and Technology, Government of India, through the Young Scientist Scheme (Sanction no. SB/YS/LS-195/2014 dated October 26, 2015) to S.G.

\section{About the Authors}

Dr. Prasad is director, consultant pediatrician, and neonatologist at Shri Shubh Lal Hospital and Research Centre, Sitamarhi, Bihar, India. His primary research interest is helminth parasite infections in children. Mr. Dahal is a PhD student in the Department of Zoology, School of Life Sciences, Sikkim University, Gangtok, Sikkim, India. His research interests include helminth parasitology and transcriptomic studies of human parasitic infections with a focus on identifying diagnostic markers and drug targets.

\section{References}

1. Toledo R, Esteban JG. An update on human echinostomiasis. Trans R Soc Trop Med Hyg. 2016;110:37-45. http://dx.doi.org/ 10.1093/trstmh/trv099

2. Lane C. Artyfechinostomum sufrartyfex. A new parasitic echinostome of man. J Med Res. 1915;2:977-83.

3. Reddy DG, Varmah K. Paryphostomum sufrartyfex (intestinal fluke) infection in man. Ind Med Gaz. 1950;85:546-7.

4. Skrjabin KI, Baschkirova EI. Trematodes of animals and man. Osnovy Trematodologii. 1956;12:53-930.

5. Kostadinova A. Family Echinostomatidae. In: Jones A, Bray RA, Gibson D, editors. Keys to the Trematoda. Vol. 2. Wallingford (UK): CABI Publishing and the Natural History Museum; 2005. p. 9-64.

6. Sambrook J, Russell DW. Purification of nucleic acids by extraction with phenol:chloroform. CSH Protoc. 2006;2006:pdb. prot4455. http://dx.doi.org/10.1101/pdb.prot4455

7. Tkach V, Pawlowski J, Mariaux J. Phylogenetic analysis of the suborder Plagiorchiata (Platyhelminthes, Digenea) based on partial lsrDNA sequences. Int J Parasitol. 2000;30:83-93. http://dx.doi.org/10.1016/S0020-7519(99)00163-0

8. Bowles J, Blair D, McManus DP. A molecular phylogeny of the human schistosomes. Mol Phylogenet Evol. 1995;4:103-9. http://dx.doi.org/10.1006/mpev.1995.1011

9. Blair D, Agatsuma T, Watanobe T, Okamoto M, Ito A. Geographical genetic structure within the human lung fluke, Paragonimus westermani, detected from DNA sequences. Parasitology. 1997;115:411-7. http://dx.doi.org/10.1017/S0031182097001534

10. Moszczynska A, Locke SA, McLaughlin JD, Marcogliese DJ, Crease TJ. Development of primers for the mitochondrial cytochrome c oxidase I gene in digenetic trematodes (Platyhelminthes) illustrates the challenge of barcoding parasitic helminths. Mol Ecol Resour. 2009;9(Suppl s1):75-82. http://dx.doi.org/10.1111/j.1755-0998.2009.02634.x

Address for correspondence: Sudeep Ghatani, Department of Zoology, School of Life Sciences, Sikkim University, Gangtok, Sikkim, India; email:sghatani@cus.ac.in 